\title{
Asymmetric Anionic Oligomerization of $N$-Substituted Citraconimide with the Chiral Ligand-Organometal Complex
}

\author{
Tsutomu OIsHi, $^{\dagger}$ Kenjiro Onimura, Wakako Sumida, \\ Hua ZHOU, and Hiromori TsuTsumI \\ Department of Applied Chemistry \& Chemical Engineering, \\ Faculty of Engineering, Yamaguchi University, \\ 2-16-1 Tokiwadai, Ube, Yamaguchi 755-8611, Japan
}

(Received October 1, 1999)

\begin{abstract}
Asymmetric anionic homopolymerizations of achiral $N$-substituted citraconimide (RCI, $N$-substituent: $\mathrm{R}=n$-propyl $(n$-PrCI), $n$-butyl $(n$-BuCI), cyclohexyl (CHCI), phenyl (PhCI), benzyl (BzCI), 1-naphthyl (NCI), 4-(ethoxycarbonyl)phenyl (ECPCI), and $\alpha$-methylbenzyl (MBzCI)) were performed with the chiral ligand-organometal complex in toluene or tetrahydrofuran (THF). The obtained oligo(RCI)s had very low molecular weights and relatively narrow polydispersity. The oligomers showed specific rotation $\left(\lceil\alpha]_{435}^{25}+79.2^{\circ}\right.$ to $\left.-40.3^{\circ}\right)$. Asymmetric induction took place on the polymer main chain and was confirmed by circular dichroism (CD) and GPC analysis using UV and polarimetric detectors.

KEY WORDS Asymmetric Anionic Polymerization / N-Substituted Citraconimide / Chiral Ligands / Chiral Polymer /
\end{abstract}

The syntheses and applications of optically active polymers have been reported. ${ }^{1}$ Okamoto and co-workers investigated the syntheses of one-handed helical polymers by asymmetric polymerizations of vinyl and isocyanate monomers. ${ }^{1-4}$ We have studied polymerizations and copolymerizations of optically active 1,2-disubstituted ethylene type monomers, i.e., chiral $N$-substituted maleimide (RMI) ${ }^{5-9}$ Asymmetric synthesis polymerizations of achiral RMI were also investigated. ${ }^{10-16}$ In these papers, the authors reported that chiral complexes of $n$-BuLi with optically active bisoxazoline derivatives were very efficient catalysts for asymmetric polymerizations of $\mathrm{RMI}^{12-14}$ and specific rotations of poly(PhMI) were much improved. We clarified that asymmetric anionic polymerizations of $N$-1-naphthylmaleimide (NMI) with chiral bisoxazoline-diethylzinc $\left(\mathrm{Et}_{2} \mathrm{Zn}\right)$ complex gave polymers having very high specific rotation $\left([\alpha]_{435}^{25}\right.$ $\left.190.5^{\circ}\right)$ and that the main chain of the polymers with dextro-rotation has more $(S, S)$ than $(R, R)$ absolute configuration from exciton chirality method. ${ }^{16}$

A cyclic olefin monomer with a $\mathrm{C}_{2}$ axis of symmetry such as RMI is polymerized to give a polymer, in which all asymmetric centers in the main chain are not always true chiral ones. Only if the main chain possesses in excess one of two enantiomeric trans (threo-diisotactic) structures, i.e., $(S, S)$ - and $(R, R)$-, the poly(RMI) can be optically active.

A cyclic olefin monomer without a $\mathrm{C}_{2}$ axis of symmetry is polymerized to give a polymer, in which all asymmetric centers in the main chain are true chiral ones. Natta, Farina, and co-workers first succeeded in asymmetric synthesis homopolymerizations of a cyclic olefin without a $\mathrm{C}_{2}$ axis of symmetry. Benzofuran was polymerized with $\mathrm{AlEtCl}_{2}$ or $\mathrm{AlCl}_{3}$ in the presence of optically active co-catalysts such as (-)- $\beta$-phenylalanine, 10camphorsulfonic acid and burucine to obtain optically active polymers consisting of chiral erythro- and threo- diisotactic structures with specific rotation $\left([\alpha]_{D}\right)$ of $+13.1^{\circ}$ to $-33.1^{\circ}$ in $\mathrm{AlEtCl}_{2}$ systems and $+56.7^{\circ}$ as the highest value in $\mathrm{AlCl}_{3}$ systems. ${ }^{17-20}$ Fueno, Furukawa, and co-workers reported polymerizations of benzofuran with various chiral initiator systems at $-75^{\circ} \mathrm{C}$. The polymers are optically active $\left([\alpha]_{\mathrm{D}}+10.4^{\circ}\right.$ to $\left.+79.4^{\circ}\right)$. Several catalyst systems consisting of aluminum chloride and (-)-menthoxy group, or a binary catalyst system consisting of aluminum chloride and (-)menthoxytriethylmetals (metal $=\mathrm{Si}, \mathrm{Ge}, \mathrm{Sn}$ ) are used as initiators. ${ }^{21,22}$ We studied asymmetric polymerizations of $N$-substituted isomaleimides (RIMI) with $n$ butyllithium $(n-\mathrm{BuLi}) /(-)$-sparteine $((-)-\mathrm{Sp}){ }^{23}$ The poly(RIMI) consists of both structures of RMI ( $60 \mathrm{~mol} \%)$ and RIMI (40 mol\%). Poly(RIMI) showed optical activity $\left([\alpha]_{D}-22.3^{\circ}\right.$ to $\left.+16.6^{\circ}\right)$ attributable to threo- and / or erythro-diisotactic structures of RIMI units.

$N$-Substituted citraconimide (RCI) has a five membered cyclic imide structure but no $\mathrm{C}_{2}$ axis of symmetry. Thus, chirality of the polymers obtained from asymmetric polymerization of $\mathrm{RCI}$ is expected to be different from that of RMI polymers which exhibit optical activity only when the polymers consist of threo-diisotactic structures. In the case of poly(RCI), there may be optical activity even though poly(RCI) has threo-disyndiotactic structures, as shown in Scheme 1. We reported the radical copolymerizations of RCI so far. ${ }^{24}$ More recently, Hagiwara and Narita briefly reported the polymerization of RCI with alkoxy metal. ${ }^{25}$ However, there have been no articles on asymmetric anionic polymerizations of RCI.

This paper describes asymmetric anionic polymerizations of RCI with chiral ligand-organometal complex, as shown in Scheme 2. All polymers showed optical activity, but specific rotations of the polymers were relatively low, compared with poly(RMI)s. The molecular weights of polymers were very low and oligomers had three to

\footnotetext{
${ }_{\dagger_{T}}$ To whom all correspondence should be addressed (Tel \& Fax: +81-836-85-9281, E-mail: oishi@po.cc.yamaguchi-u.ac.jp).
} 
Threo-diisotactic structures
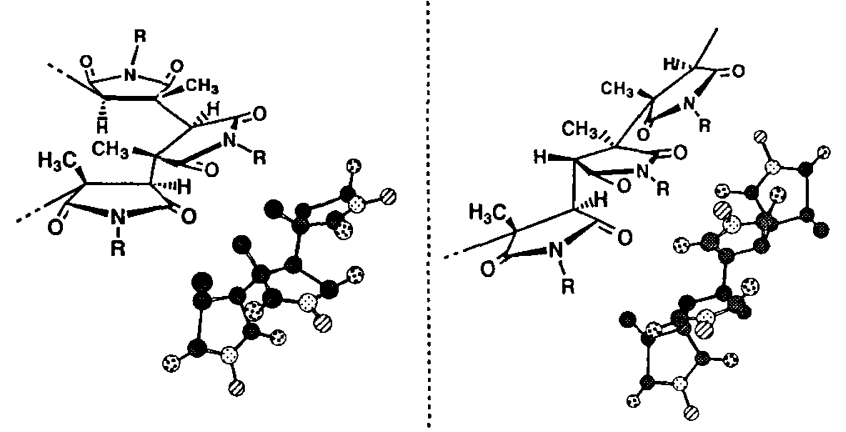

Threo-disyndiotactic structures

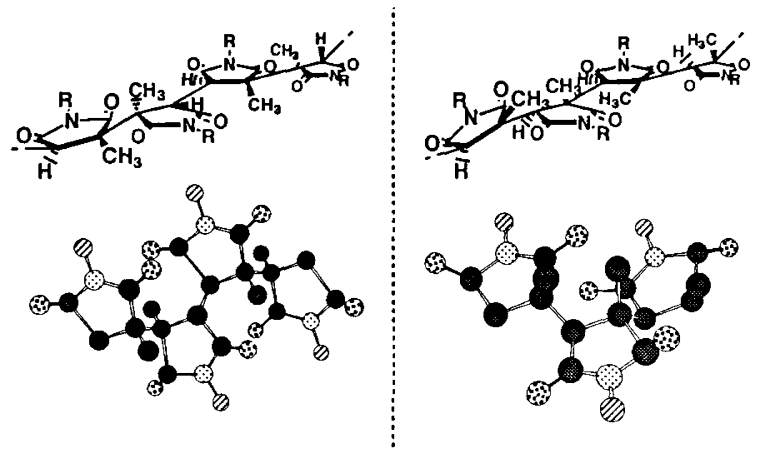

Scheme 1.

four units of RCI. Structures and chiroptical properties of the oligomers were investigated by ${ }^{1} \mathrm{H}$ and ${ }^{13} \mathrm{C}$ NMR spectra, circular dichroism (CD) spectroscopy and GPC analysis with UV and polarimetric detectors.

\section{EXPERIMENTAL}

\section{RCI Monomers}

RCI was prepared from citraconic anhydride and the corresponding primary amine by a method reported lately. ${ }^{26}$ The obtained RCI was identified by ${ }^{1} \mathrm{H}$ NMR spectra. Melting and boiling points of RCI are as follows: $n$-propyl ( $n$-PrCI) bp. $113^{\circ} \mathrm{C} / 26 \mathrm{mmHg}, n$-butyl ( $n$-BuCI) bp. $125^{\circ} \mathrm{C} / 21 \mathrm{mmHg}$, cyclohexyl (CHCI) mp. $104-106^{\circ} \mathrm{C}$, phenyl (PhCI) mp. $95^{\circ} \mathrm{C}$, benzyl $(\mathrm{BzCI}) 188^{\circ} \mathrm{C} / 18 \mathrm{mmHg}$, 1-naphthyl (NCI) mp. 136-138 $\mathrm{C}$, 4-(ethoxycarbonyl)phenyl (ECPCI) mp. $77^{\circ} \mathrm{C}$, and $\alpha$-methylbenzyl (MBzCI) bp. $135^{\circ} \mathrm{C} / 0.2 \mathrm{mmHg}$.

\section{Reagents and Solvents}

Commercially available $n$-BuLi $\left(1.63 \mathrm{~mol} \mathrm{~L}^{-1}\right.$ in a hexane solution) was used without further purification. The concentration of $n$-BuLi was precisely determined by titration. Azobisisobutyronitrile (AIBN) and benzoylperoxide (BPO) were purified by usual methods. Solvents, toluene, THF and methanol were purified by usual methods. (-)-Sp was purchased and purified by distillation just before use $\left([\alpha]_{435}^{25}=-10.3^{\circ}\left(c 1.0 \mathrm{~g} \mathrm{dL}^{-1}\right.\right.$, $l=10 \mathrm{~cm}$, THF). (4S )-2,2'-(1-Ethylpropylidene)bis (4benzyl-4,5-dihydrooxazole)(Bnbox $)^{27}$ and $(S, S)-(+)-2,3-$ dimethoxy-1,4-bis(dimethylamino)butane (DDB) ${ }^{28}$ were synthesized by the published procedure, Bnbox: $[\alpha]_{435}^{25}=$ $-150.7^{\circ}$ and DDB: $[\alpha]_{435}^{25}=+19.8^{\circ}$ (c $1.0 \mathrm{~g} \mathrm{dL}^{-1}, l=10$ $\mathrm{cm}, \mathrm{THF})$.

\section{Polymerization}

Anionic homopolymerizations of RCI were carried out in toluene or THF under dry nitrogen atmosphere. A chiral ligand and organometal were mixed at $0^{\circ} \mathrm{C}$ just before use. FlLi was prepared by adding 1 equiv. of $n-\mathrm{BuLi}$ to a solution of fluorene in toluene or THF at room temperature. An initiator solution was added to the monomer solution cooled to $0^{\circ} \mathrm{C}$. The reaction was terminated by the addition of a few drops of methanol. The polymer was precipitated in excess methanol containing a small amount of hydrochloric acid, separated by filtration, and purified by reprecipitation from THF-methanol systems three times.

\section{Measurements}

Gel permeation chromatography (GPC) measurement of polymers was accomplished on a LC-10 AS (Shimadzu) equipped with a UV $(254 \mathrm{~nm})$ detector SPD-A (Shimadzu) and on a polarimetric detector OR-990 (Japan Spectroscopic Co.) using $\mathrm{THF}$ as eluent at $50^{\circ} \mathrm{C}$. Four GPC columns HSG-10, 15, 20, 40H (Shimadzu) were connected in series, and molecular weight was calibrated with standard polystyrene. High performance liquid chromatography (HPLC) measurement was performed on a LC-10 AS (Shimadzu) using JASCO Finepak SIL $\mathrm{C}_{18}$ and $\mathrm{H}_{2} \mathrm{O}-\mathrm{MeOH}$ as eluent at r.t. Hg-line specific optical rotations were measured with a JASCO DIP-140 (Japan Spectroscopic Co.) at $25^{\circ} \mathrm{C}$ (quartz cell length, 10 or $5 \mathrm{~cm} ; 1.0 \mathrm{~g} \mathrm{dL}^{-1}$ in THF). Vapor pressure osmometer measurement was carried out in THF with a Model 114 apparatus (Corona Electric Co., Ltd. Japan). Circular dichroism (CD) spectra were obtained at $25^{\circ} \mathrm{C}$ using a JASCO J-20 C (Japan Spectroscopic Co.), equipped with a xenon source and a computing data processor (quartz cell length, 0.1 and $0.2 \mathrm{~mm}$; $c a 0.5-$ $1.0 \mathrm{~g} \mathrm{dL}^{-1}$ in THF). Ultraviolet (UV) spectra were obtained with a Shimadzu UV 2200 spectrophotometer (quartz cell length, $1 \mathrm{~mm}$; $c a 0.05-0.1 \mathrm{~g} \mathrm{dL}^{-1}$ in THF) ${ }^{1} \mathrm{H}$ and ${ }^{13} \mathrm{C}$ NMR spectra of polymers were measured in chloroform- $d$ at room temperature in the presence of tetramethylsilane (TMS) as the internal standard using a JEOL EX-270 $\left({ }^{1} \mathrm{H}, 270 \mathrm{MHz},{ }^{13} \mathrm{C}, 68.7 \mathrm{MHz}\right)$ spectrometer.

\section{RESULTS AND DISCUSSION}

\section{Anionic Polymerization of RCI}

Anionic and radical polymerizations of RCI were performed with $n-\mathrm{BuLi}, \mathrm{Et}_{2} \mathrm{Zn}, \mathrm{BPO}$ and $\mathrm{AIBN}$ at r.t. and $60^{\circ} \mathrm{C}$ for 24 to $96 \mathrm{~h}$, as shown in Scheme 2. Table I shows the results of the polymerizations of RCI. Yields of polymers obtained with anionic initiators were insolublepart in hexane, and $10.1 \%$ to $94.2 \%$. The hexane solublepart was RCI monomer having aryl groups, judging from the ${ }^{1} \mathrm{H}$ NMR spectrum of the residue after concentration of the hexane solution. The yields of oligo(RCI)s having aryl groups (Table I, run 2, 3, 6-10, 12-14) were larger than those of oligo(RCI) bearing $N$-alkyl substituents (Table I, run 15-17). The reason may be the solubility of oligomers. That is, oligo(RCI) having alkyl groups could not be completely recovered even using hexane as a precipitant. The number-average molecular weight 
$\left(\bar{M}_{n}\right)$ was 300 to 700 and polydispersity was 1.1 to 2.0 . $\bar{M}_{n}$ was so low that the oligomers were very soluble in organic solvents such as methanol, THF, toluene and chloroform. In the case of polymerizations of cyclic olefin such as RMI and RCI, the initiator needs higher concentration than that for general vinyl polymerizations to obtain appreciable polymers within limited polymerization time ( 24 to $96 \mathrm{~h}$ ) because of low polymerizability. The polymerization of RCI needed initiator concentration of 10 mol\% of the RCI to obtain enough yield. For the radical polymerization of RCI, yields were much lower than those for anionic polymerizations (run 18,19 ). $\bar{M}_{n}$ and polydispersity $\left(\bar{M}_{w} / \bar{M}_{n}\right)$ of poly(NMI) were 500 and 1.3 , respectively, the same as by anionic polymerization. The polymerization of $n$-BuCI with AIBN in bulk gave poly( $n$-BuCI) insoluble in methanol with $\bar{M}_{n}$ of $6.3 \times 10^{3}$ in yield of $4.3 \%$. The low polymerizability was attributed to steric hindrance of $\alpha$-methyl group on the maleimide ring. Compared to methacrylates with acrylates, the polymerizability of methacrylate was higher than that of acrylate. ${ }^{29,30}$ However, the polymerizability of RCI with a methyl group was lower than that of RMI without a methyl group. This may result from steric hindrance due to a 1,1,2-trisubstituted ethylene type monomer of RCI, compared with RMI of 1,2-disubstituted ethylene type monomer. Thus, RCI exhibited lower polymerizability than that of RMI. Consequently, there have been few reports on the homopolymerization of RCI though radical copolymerizations of RCI with vinyl monomers were studied. ${ }^{24}$ Very recently Hagiwara and Narita ${ }^{25}$ reported that anionic homopolymerizations of $\mathrm{PhCI}$ were carried out with $t$-butoxy potassium at $0^{\circ} \mathrm{C}$ for 7 days to obtain oligomers having $\bar{M}_{n}$ of 400 . But the yields were very low $(0.8$ to $57 \%)$, as in our experiments.

Figures 1 and 2 depict extended ${ }^{1} \mathrm{H}$ and ${ }^{13} \mathrm{C}$ NMR spec- tra for parts of phenyl and carbonyl groups of oligo(PhCI)s. In the ${ }^{1} \mathrm{H}$ NMR spectra, peaks (A) due to aromatic protons of the oligo( $\mathrm{PhCI})$ obtained with radical initiator were different from those $((\mathrm{B})$ and $(\mathrm{C})$ ) obtained with anionic initiators. Large difference between peaks (B) and (C) could not be observed, but peaks ( ${ }^{*}$ ) around 7.5 ppm exhibited obviously slight difference. In ${ }^{13} \mathrm{C}$ NMR spectra, signals assigned to aromatic carbons of the oligo(PhCI) obtained with anionic initiator were similar, as in Figure $2((\mathrm{~B})$ and $(\mathrm{C})$ ), and significantly different from that obtained with radical initiator (A). Re-
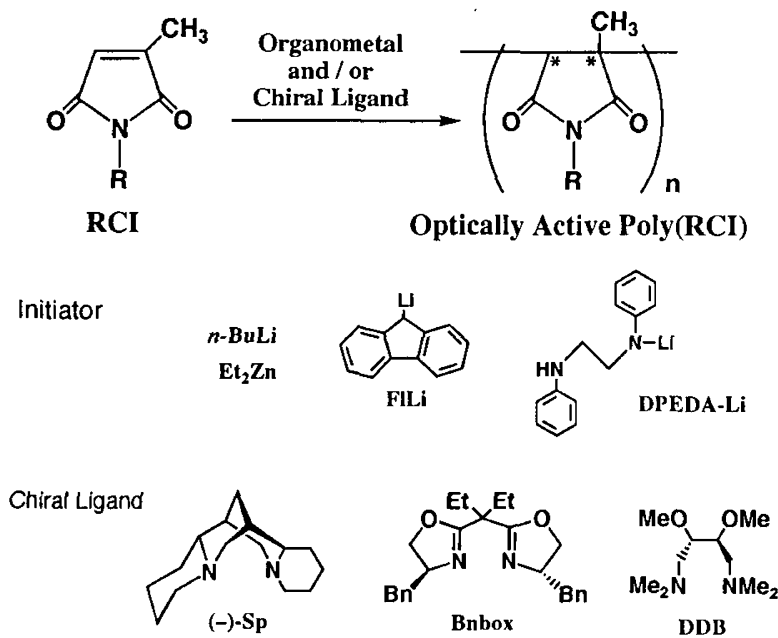

N-Substituents

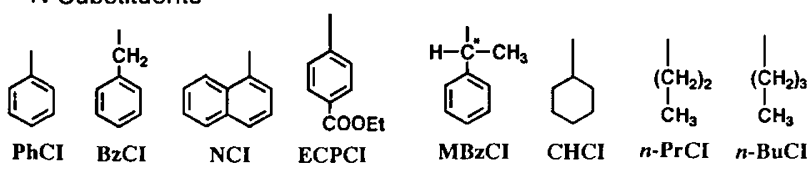

Scheme 2.

Table I. Anionic and radical polymerizations of RCI ${ }^{a}$

\begin{tabular}{|c|c|c|c|c|c|c|c|}
\hline \multirow{3}{*}{ Run } & \multirow{3}{*}{ Monomer $^{b}$} & \multirow{3}{*}{$\begin{array}{c}\text { Initiator } \\
\text { mol\% }\end{array}$} & \multirow{3}{*}{ Solvent } & \multirow{3}{*}{ Polym. time } & \multirow{3}{*}{$\frac{\text { Yield }^{\mathrm{c}}}{\%}$} & \multirow{3}{*}{$\bar{M}_{n}^{\mathrm{d}}$} & \multirow{3}{*}{$\bar{M}_{w} / \bar{M}_{n}$} \\
\hline & & & & & & & \\
\hline & & & & & & & \\
\hline 1 & PhCI & $n$-BuLi (2) & Tol. (5) & 96 & 20.4 & 430 & 1.3 \\
\hline 2 & PhCI & $n$-BuLi (10) & Tol. (10) & 24 & 62.9 & 390 & 1.3 \\
\hline 3 & PhCI & n-BuLi (10) & Tol. (10) & 96 & 94.2 & 370 & 1.3 \\
\hline 4 & $\mathrm{PhCI}$ & $\mathrm{Et}_{2} \mathrm{Zn}(10)$ & Tol. (10) & 96 & 12.9 & 350 & 1.2 \\
\hline 5 & $\mathrm{BzCI}$ & $n$-BuLi (1) & Tol. (10) & 24 & 2.7 & 610 & 1.1 \\
\hline 6 & $\mathrm{BzCI}$ & $n-\mathrm{BuLi}(5)$ & Tol. (10) & 24 & 67.6 & $480(510)^{\mathrm{e}}$ & 1.3 \\
\hline 7 & $\mathrm{BzCI}$ & $n$-BuLi (10) & Tol. (10) & 24 & 77.7 & $480(540)^{\mathrm{e}}$ & 1.3 \\
\hline 8 & $\mathrm{BzCI}$ & $n-\operatorname{BuLi}(10)$ & Tol. (10) & 48 & 74.3 & $540(550)^{\mathrm{e}}$ & 1.2 \\
\hline 9 & $\mathrm{BzCI}$ & $n$-BuLi (10) & Tol. (10) & 72 & 73.8 & $500(690)^{\mathrm{e}}$ & 1.3 \\
\hline 10 & $\mathrm{BzCI}$ & $n$-BuLi (10) & Tol. (10) & 96 & 78.4 & 550 & 1.2 \\
\hline 11 & $\mathrm{BzCI}$ & $\mathrm{Et}_{2} \mathrm{Zn}(10)$ & Tol. (10) & 96 & 10.1 & 310 & 1.4 \\
\hline 12 & ECPCI & $n$-BuLi (10) & Tol. (5) & 24 & 86.9 & 610 & 1.3 \\
\hline 13 & NCI & $n-\operatorname{BuLi}(10)$ & Tol. (13) & 24 & 63.2 & 460 & 1.3 \\
\hline 15 & CHCI & $n-\operatorname{BuLi}(10)$ & Tol. (10) & 24 & 10.1 & 700 & 2.0 \\
\hline 16 & $n$-BuCI & $n-\operatorname{BuLi}(10)$ & Tol. (10) & 24 & 10.1 & 540 & 1.4 \\
\hline 17 & $n$-PrCI & $n-\operatorname{BuLi}(10)$ & Tol. (10) & 24 & 11.3 & 530 & 1.2 \\
\hline 18 & $\mathrm{NCI}$ & AIBN & THF (4) & 48 & 5.6 & 480 & 1.3 \\
\hline 19 & $n$-BuCI & $\operatorname{AIBN}(\mathbf{1})$ & Bulk & 48 & $4.3^{f}$ & 6300 & 1.2 \\
\hline 20 & PhCI & $\mathrm{BPO}(2)$ & Bulk $^{\mathrm{g}}$ & 24 & 8.7 & 470 & 1.4 \\
\hline
\end{tabular}

${ }^{a}$ Anionic polymerization at r.t., radical polymerization at $60{ }^{\circ} \mathrm{C} .{ }^{\mathrm{b}} \mathrm{RCI} 0.5 \mathrm{~g} .{ }^{\mathrm{c}}$ Hexane-insoluble. ${ }^{\mathrm{d}}$ By GPC. ${ }^{\mathrm{e}}$ By VPO. ${ }^{\mathrm{f}} \mathrm{MeOH}-\mathrm{insoluble}$.

${ }^{\mathrm{g}}$ At $120^{\circ} \mathrm{C}$. 
garding carbonyl carbons, there were large differences in curves (A), (B), and (C). That is, large three peaks for oligo(PhCI) obtained from radical initiator were observed (A), and four large peaks appeared in the oligo(PhCI) obtained with anionic initiator $(B)$ and $(\mathrm{C})$. These different peaks could not be attributed to differences in molecular weights because three oligomers have similar $\bar{M}_{n} \mathrm{~s}\left(\bar{M}_{n}=470\right.$ for A, $\bar{M}_{n}=370$ for B and $\bar{M}_{n}=430$ for C). The structure of oligo(RCI) obtained from anionic initiator may thus be different from that obtained with radical initiator. In the oligo(PhCI)s obtained with anionic initiator, however, the differences of structure of oligo$(\mathrm{PhCI})$ between with and without chiral ligand could not be sufficiently clarified by NMR data at present. Poly(RCI) may consist of mixtures of threo-diisotactic and disyndiotactic structures, as demonstrated in Scheme 1.

\section{Asymmetric Anionic Polymerization of RCI}

Asymmetric anionic polymerizations of RCI were carried out with chiral ligand and organometal complex shown in Scheme 1.

Table II summarizes the results of the asymmetric polymerization of RCI with (-)-Sp/organometal complex at r.t. for $96 \mathrm{~h}$. Some oligo(RCI) were very low yields and impossible to measure $\bar{M}_{n}$ and specific rotation. But some oligo(RCI) were optically active and $[\alpha]_{435}^{25}$ was
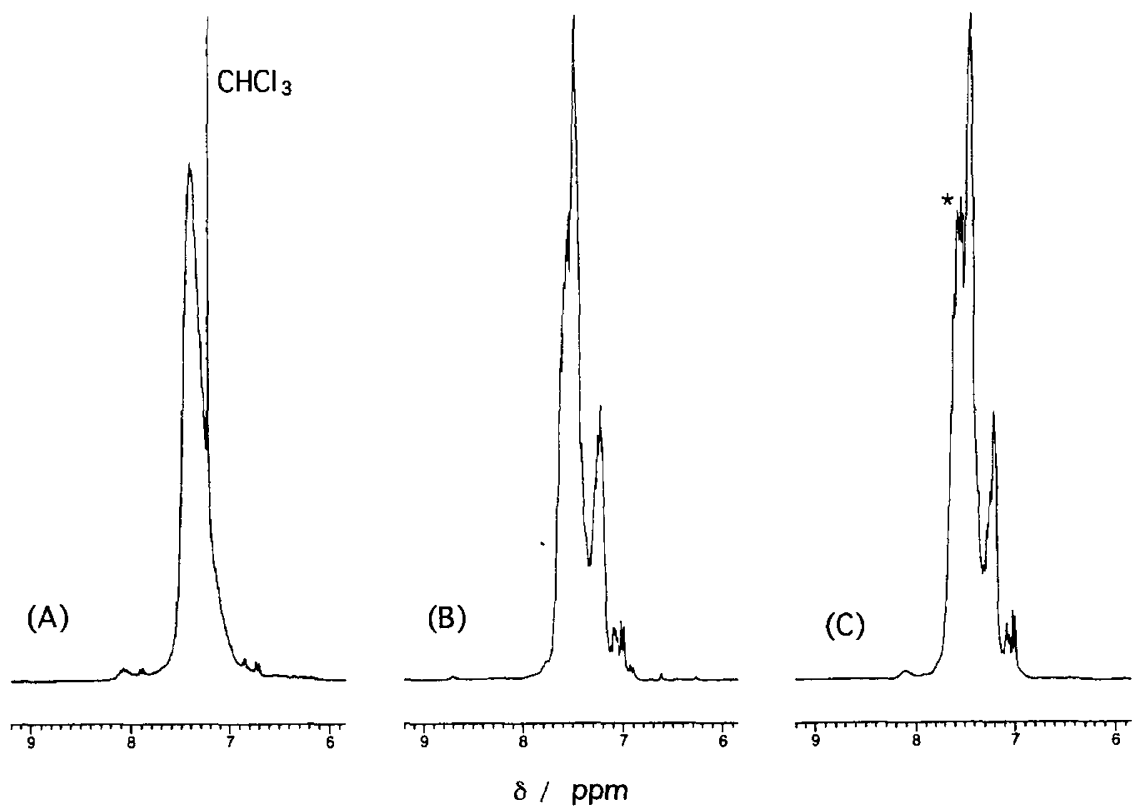

Figure 1. ${ }^{1} \mathrm{H}$ NMR spectra of poly(PhCI) obtained with (A) radical initiator (Table I, run 20), (B) $n$-BuLi (Table I, run 3) and (C) Bnbox/Et ${ }_{2} \mathrm{Zn}$ (Table III, run 2).
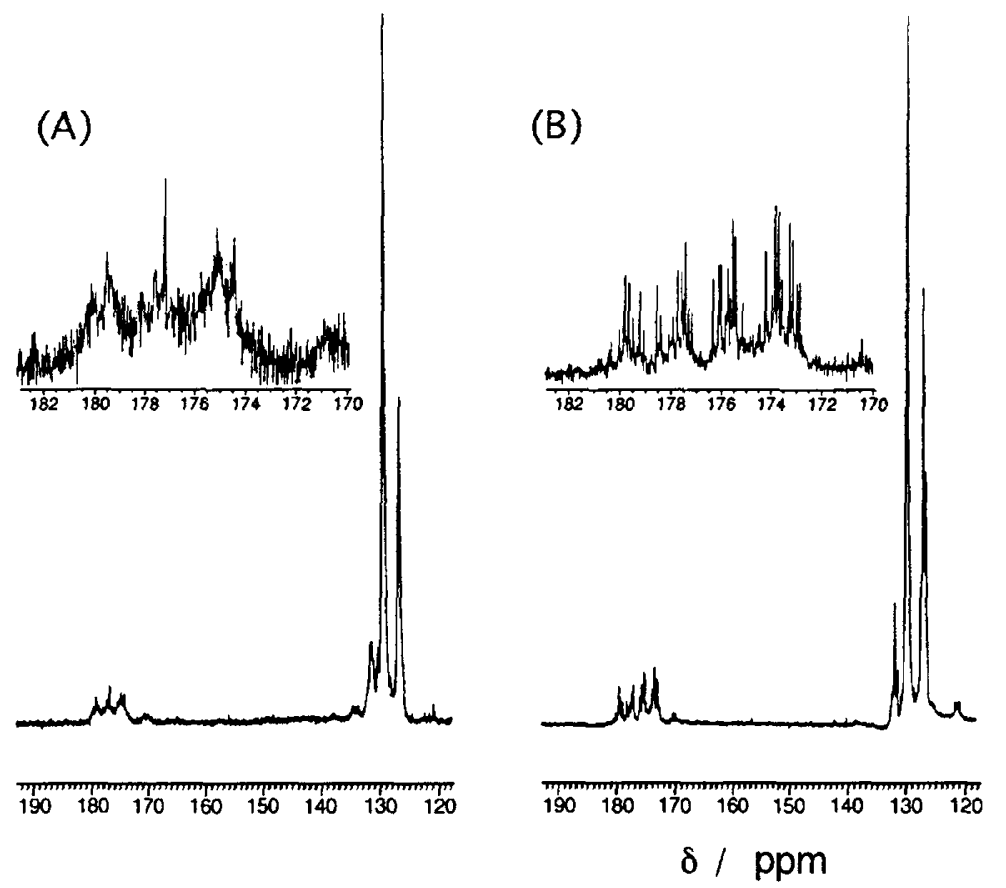

(C)

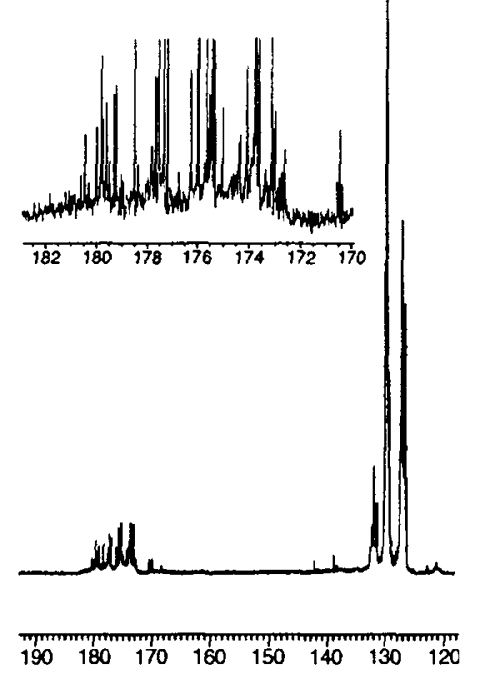

Figure 2. Expanded ${ }^{13} \mathrm{C}$ NMR spectra for poly(PhCI) obtained with (A) radical initiator (Table I, run 20), (B) $n$-BuLi (Table I, run 2) and (C) Bnbox/Et $2 \mathrm{Zn}$ (Table III, run 2). 
Table II. Anionic polymerizations of RCI with (-)-Sp/organometal at r.t. for $96 \mathrm{~h}$

\begin{tabular}{|c|c|c|c|c|c|c|c|}
\hline \multirow{2}{*}{ Run } & \multirow{2}{*}{ Monomer $^{a}$} & Initiator $^{b}$ & Solvent & Yield $^{c}$ & \multirow{2}{*}{$\bar{M}_{n}^{\mathrm{d}}$} & \multirow{2}{*}{$\bar{M}_{u^{\prime}} / \bar{M}_{n}{ }^{d}$} & \multirow{2}{*}{$\begin{array}{c}{[\alpha]_{435}^{25}{ }^{25}} \\
\text { deg. }\end{array}$} \\
\hline & & $\operatorname{mol} \%$ & $\mathrm{~mL}$ & $\%$ & & & \\
\hline 1 & PhCI & $n$-BuLi (10) & Tol. (10) & 75.2 & 410 & 1.3 & 8.0 \\
\hline 2 & PhCI & FlLi (10) & Tol. (10) & 72.4 & 440 & 1.3 & 11.1 \\
\hline 3 & PhCI & DPEDA-Li (10) & Tol. (10) & 89.9 & 400 & 1.3 & 6.7 \\
\hline 4 & PhCI & $\mathrm{Et}_{2} \mathrm{Zn}(10)$ & Tol. (10) & 27.2 & 310 & 1.3 & 7.1 \\
\hline 5 & $\mathrm{BzCI}$ & $n-\operatorname{BuLi}(10)$ & Tol. (10) & 44.1 & 600 & 1.2 & -8.3 \\
\hline 6 & $\mathrm{BzCI}$ & $\mathrm{Et}_{2} \mathrm{Zn}(10)$ & Tol. (10) & 17.2 & 570 & 1.2 & $-40.3^{\mathrm{f}}$ \\
\hline 7 & NCI & $n-\mathrm{BuLi}(10)$ & Tol. (13) & 100 & 490 & 1.3 & 1.9 \\
\hline 8 & NCI & $\mathrm{Et}_{2} \mathrm{Zn}(10)$ & Tol. (13) & 90.0 & 480 & 1.4 & 11.0 \\
\hline 9 & NCI & $\mathrm{Et}_{2} \mathrm{Zn}(10)$ & THF (5) & 100 & 490 & 1.3 & 11.5 \\
\hline 10 & ECPCI & $n$-BuLi (10) & Tol. (5) & 90.1 & 600 & 1.3 & 6.1 \\
\hline 11 & $\mathrm{MBzCI}$ & $n$-BuLi (10) & Tol. (10) & 30.9 & 600 & 1.2 & 4.9 \\
\hline 12 & $\mathrm{MBz} \mathrm{CI}$ & $E t_{2} \operatorname{Zn}(10)$ & Tol. (10) & Trace & $-g$ & $-g$ & $-g$ \\
\hline 13 & $\mathrm{CHCI}$ & $n$-BuLi (10) & Tol. (10) & 15.4 & -g $^{\prime}$ & $-g$ & $-g$ \\
\hline 14 & CHCI & $\mathrm{Et}_{2} \mathrm{Zn}(10)$ & Tol. $(10)$ & 6.9 & $-\stackrel{2}{-2}$ & $-^{\mathrm{g}}$ & $-g$ \\
\hline 15 & $n-\operatorname{PrCI}$ & $n$-BuLi (10) & Tol. (10) & Trace & $-\varepsilon$ & $-g$ & $-g$ \\
\hline 16 & $n$-PrCI & $\mathrm{Et}_{2} \mathrm{Zn}(10)$ & Tol. (10) & Trace & $-g$ & $-g$ & $-g$ \\
\hline
\end{tabular}

Table III. Anionic polymerizations of RCI with Bnbox/organometal at r.t. for $96 \mathrm{~h}$

\begin{tabular}{|c|c|c|c|c|c|c|c|}
\hline \multirow{2}{*}{ Run } & \multirow{2}{*}{ Monomer $^{\text {a }}$} & Initiator $^{b}$ & Solvent & Yield $^{c}$ & \multirow{2}{*}{$\bar{M}_{n}^{\mathrm{d}}$} & \multirow{2}{*}{$\bar{M}_{w} / \bar{M}_{n}^{\mathrm{d}}$} & \multirow{2}{*}{$\frac{[\alpha]_{435}^{25}{ }^{e}}{\operatorname{deg} .}$} \\
\hline & & mol\% & $\mathrm{mL}$ & $\%$ & & & \\
\hline 1 & $\mathrm{PhCI}$ & $n-\operatorname{BuLi}(10)$ & Tol. (10) & 100 & 450 & 1.4 & -9.1 \\
\hline 2 & PhCI & $\mathrm{Et}_{\mathrm{z}} \mathrm{Zn}(10)$ & Tol. (10) & 100 & 430 & 1.3 & 23.7 \\
\hline 3 & $\mathrm{BzCI}$ & $n-\mathrm{BuLi}(10)$ & Tol. (10) & 82.6 & 530 & 1.3 & -0.6 \\
\hline 4 & $\mathrm{BzCI}$ & $\mathrm{Et}_{2} \mathrm{Zn}(10)$ & Tol. (10) & 55.8 & 640 & 1.2 & 14.0 \\
\hline 5 & NCI & $n$-BuLi (10) & Tol. (13) & 100 & 470 & 1.3 & -2.4 \\
\hline 6 & NCI & $\mathrm{Et}_{2} \mathrm{Zn}(10)$ & Tol. (13) & 100 & 400 & 1.4 & 33.7 \\
\hline 7 & $n-\mathrm{BuCI}$ & $n-\operatorname{BuLi}(10)$ & Tol. (5) & Trace & -1 & $-{ }^{r}$ & -1 \\
\hline
\end{tabular}

$+11.5^{\circ}$ to $-40.3^{\circ}$. Optical activity of oligo(RCI) was influenced by $N$-substituents and organometal. Oligo$(\mathrm{BzCI})$ exhibited dextro-rotation regardless of the organic metal (runs 5, 6).

Table III summarizes the results of anionic polymerizations of RCI with Bnbox-organometal complex at r.t. for $96 \mathrm{~h}$. The polymerization of $n$-BuCI gave polymers in trace yield. That is, polymerization reactivity for RCI having a very little bulky alkyl group was very low. For other systems in Table III, yields were quantitative except for BzCI. $\bar{M}_{n}$ and $\bar{M}_{w} / \bar{M}_{n}$ were 400 to 600 and 1.2 to 1.4, respectively, as in (-)-Sp/organometal systems. The polymerizations of RCI (PhCI, BzCI, and NCI) with $\mathrm{Bnbox} / n-\mathrm{BuLi}$ and $\mathrm{Bnbox} / \mathrm{Et}_{2} \mathrm{Zn}$ formed polymers with levo- and dextro-rotation, respectively. This was noted for polymerization with (-)-Sp/organometal systems.

Table IV summarizes the results of the polymerizations of RCI with DDB/organometal complex at r.t. for 96. $\mathrm{Et}_{2} \mathrm{Zn}$ gave relatively low yield of polymers. Oligomers obtained with $\mathrm{DDB} / n-\mathrm{BuLi}$ and $\mathrm{DDB} / \mathrm{Et}_{2} \mathrm{Zn}$ exhibited levo- and dextro-rotation, respectively, as in the polymerization with Bnbox systems.

\section{Chiroptical Properties and Structures of Oligomers}

The obtained oligo(RCI)s were optically active, and chirality of the oligomer was strongly influenced by organometals, chiral ligands and $N$-substituents. Generally, oligo(RCI)s showed CD peaks at the range of 220 to $280 \mathrm{~nm}$.

Typical CD and UV spectra for oligo(PhCI)s and used chiral ligands are shown in Figure 3. The obtained oligo(PhCI) exhibited quite different $\mathrm{CD}$ peaks from chiral ligands of DDB and Bnbox, suggesting that chirality of the oligomer is attributed to not the chiral ligand but stereogenicity of the oligomer main chain itself. In the chiral ligand $\mathrm{DDB} / \mathrm{Et}_{2} \mathrm{Zn}$ system, oligo(RCI) with the highest specific rotation was obtained. For more detailed information on the relationship between molecular weight and chirality of the oligomer, GPC analysis was performed using $U V$ and polarimetric detectors.

Figure 4 depicts GPC curves for oligo(PhCI) obtained with $\mathrm{Bnbox} / \mathrm{Et}_{2} \mathrm{Zn}$ and oligo(BzCI) obtained with (-)-Sp/ $\mathrm{Et}_{2} \mathrm{Zn}$. In both systems, GPC curves by UV detector almost corresponded to those by polarimetric detector, suggesting that chirality of the oligomer is attributed to not chiral carbon of the main chain-ends but chiral 
Table IV. Anionic polymerizations of RCI with DDB/organometal at r.t. for $96 \mathrm{~h}$

\begin{tabular}{|c|c|c|c|c|c|c|c|}
\hline Run & Monomer $^{a}$ & Initiator $^{b}$ & Solvent & Yield $^{c}$ & $\bar{M}_{n}^{\mathrm{d}}$ & $\bar{M}_{w} / \bar{M}_{n}^{\mathrm{d}}$ & $\frac{[\alpha]_{435}^{25} \mathrm{e}^{\mathrm{d}}}{\mathrm{deg}}$ \\
\hline 1 & $\mathrm{PhCI}$ & $n-\mathrm{BuLi}(10)$ & Tol. (10) & 72.5 & 420 & 1.3 & -8.8 \\
\hline 2 & $\mathrm{PhCI}$ & $\mathrm{Et}_{2} \mathrm{Zn}(10)$ & Tol. (10) & 12.5 & 430 & 1.2 & $79.2^{\mathrm{f}}$ \\
\hline 3 & $\mathrm{BzCI}$ & $\mathrm{Et}_{2} \mathrm{Zn}(10)$ & Tol. (10) & Trace & $-g$ & $-g$ & $-g$ \\
\hline 4 & NCI & $n-\mathrm{BuLi}(10)$ & Tol. (13) & 84.0 & 810 & 1.9 & -8.5 \\
\hline 5 & $\mathrm{NCI}$ & $\mathrm{Et}_{2} \mathrm{Zn}(10)$ & Tol. (13) & 6.5 & 490 & 1.3 & $5.2^{r}$ \\
\hline
\end{tabular}
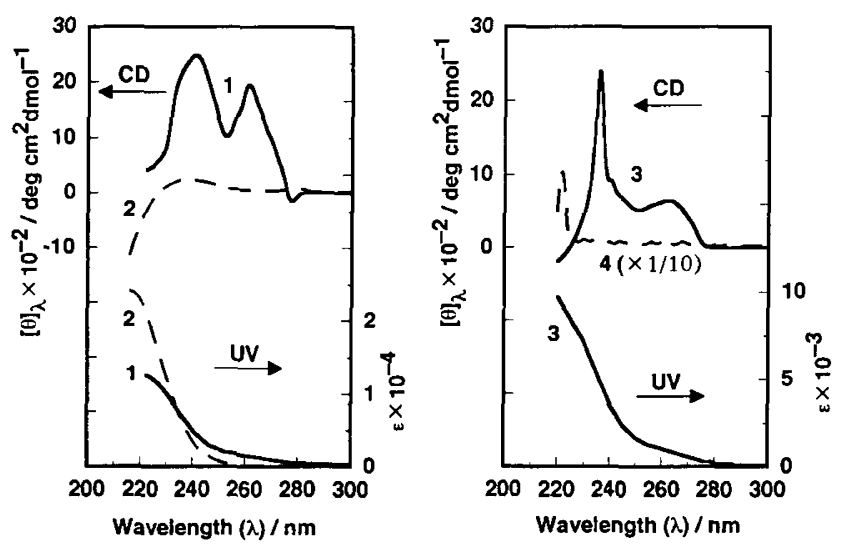

Figure 3. $\mathrm{CD}$ and UV spectra for poly(PhCI) obtained with (1) $\mathrm{DDB} / \mathrm{Et}_{2} \mathrm{Zn}$ (Table IV, run 2), (3) Bnbox / $\mathrm{Et}_{2} \mathrm{Zn}$ (Table III, run 2) and ligands (2) DDB and (4) Bnbox.
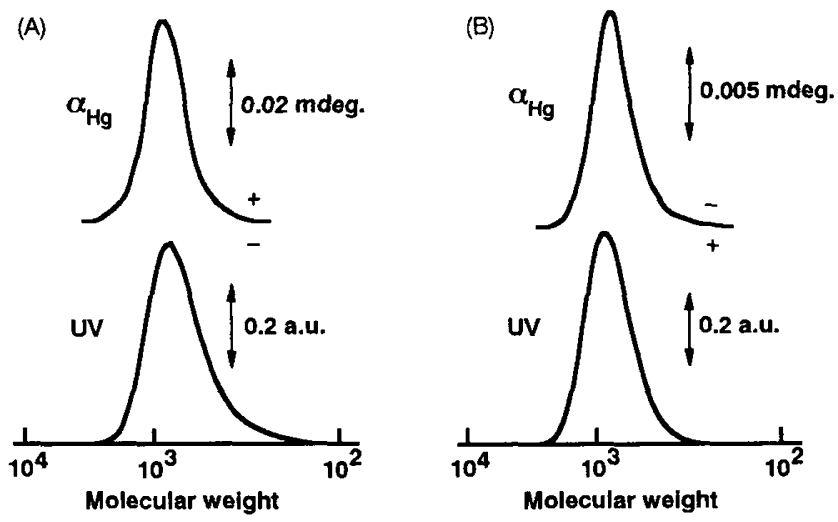

Figure 4. GPC curves of poly(PhCI) obtained with (1) Bnbox/Et $\mathrm{Zn}$ (Table III, run 2) and (2) poly(BzCI) obtained with (-)-Sp/Et Zn (Table II, run 6). Top chromatogram was obtained by polarimetric detection $\left(\alpha_{\mathrm{Hg}}\right)$ and the bottom by UV detection $(254 \mathrm{~nm})$.

stereogenicity of the main chain.

The structures and chiroptical properties of oligo(NCI) with the highest specific rotation (run 6 in Table III) were investigated in detail. Oligo(NCI)(A) was reprecipitated with mixtures of methanol and $\mathrm{H}_{2} \mathrm{O}$ to obtain oligo (NCI)(B, C, D, and E), as shown in Scheme 3. Oligo(NCI) (D) was separated using HPLC to give oligo(NCI) (F and G). HPLC charts and NMR spectra of oligo(NCI) (A to G) are shown in Figures 5 and 6, respectively. Oligo(NCI)s showed different HPLC charts, which suggests that each

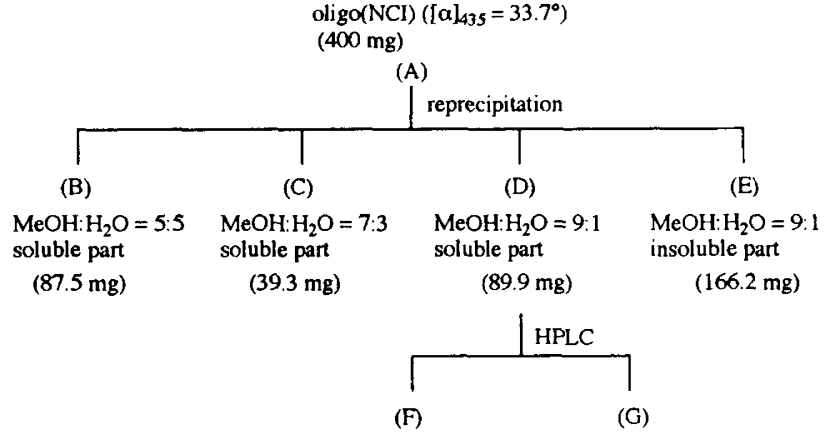

Scheme 3.

oligo(NCI) has different molecular weight and/or structure. Oligo(NCI)(B and C) showed similar NMR patterns, and oligo(NCI)(D and E) exhibited lower peaks due to ethyl groups formed from $\mathrm{Et}_{2} \mathrm{Zn}$ at the chain end, compared with oligo(NCI)(B and C). Peaks $\left({ }^{*}\right)$ at about 3 ppm in the NMR spectra of oligo(NCI)(D and E) disappeared in the spectra of oligo( $\mathrm{NCI})(\mathrm{F}$ and $\mathrm{G})$. Accordingly, the product showing the peaks $\left({ }^{*}\right)$ could be separated by HPLC, but the product could not be identified because of the trace amount.

The degree of polymerization was 1.7 to 50 , according to the ratio of integral values due to an ethyl group at the starting chain end and aromatic protons of naphthyl groups. That is, oligo(NCI)(E) had approximately 50 degrees of polymerization and corresponded to $42 \mathrm{wt} \%$ of oligo(NCI)(A). This was not consistent with GPC and VPO. Thus, we considered the polymerization mechanism without ethyl groups at the chain end, as shown in Scheme 4 (route B). Generally, the polymerization proceeds according to route A in Scheme 4 . When a methyl group such as RCI was present, the polymerization proceeded by route $B$. That is, ethyl anions formed from $\mathrm{Et}_{2} \mathrm{Zn}$ could attack protons of methyl group of RCI to afford several dimers, trimers and/or tetramers shown in Scheme 4.

Figure 7 depicts GPC curves of oligo(NCI)(A, B, and E). Whole oligo(NCI)(A) exhibited dextro-specific rotation. Oligo(NCI)(B) soluble in $\mathrm{MeOH} / \mathrm{H}_{2} \mathrm{O}=5 / 5$ showed relatively low $\bar{M}_{n}$ and both dextro- and levo-specific rotations. Oligo(NCI)(E) insoluble in $\mathrm{MeOH} / \mathrm{H}_{2} \mathrm{O}=9 / 1$ exhibited considerably high $\bar{M}_{n}$ and dextro-specific rotation $\left([\alpha]_{435}^{25}+37.7^{\circ}\right)$. 


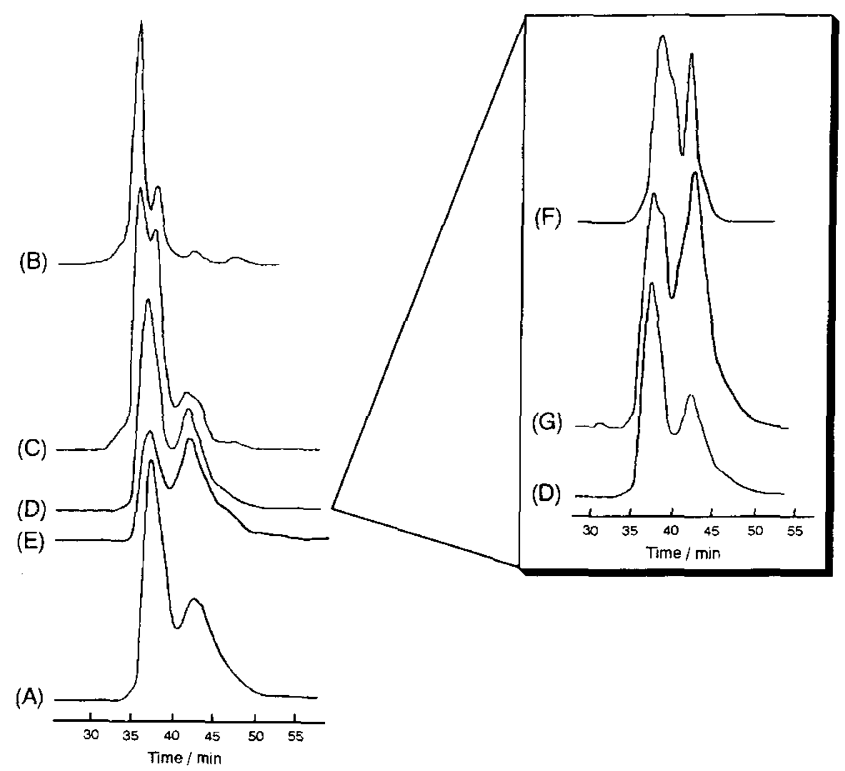

Figure 5. HPLC spectra of oligo(NCI)(A, B, C, D, E, F, and G shown in Scheme 3).

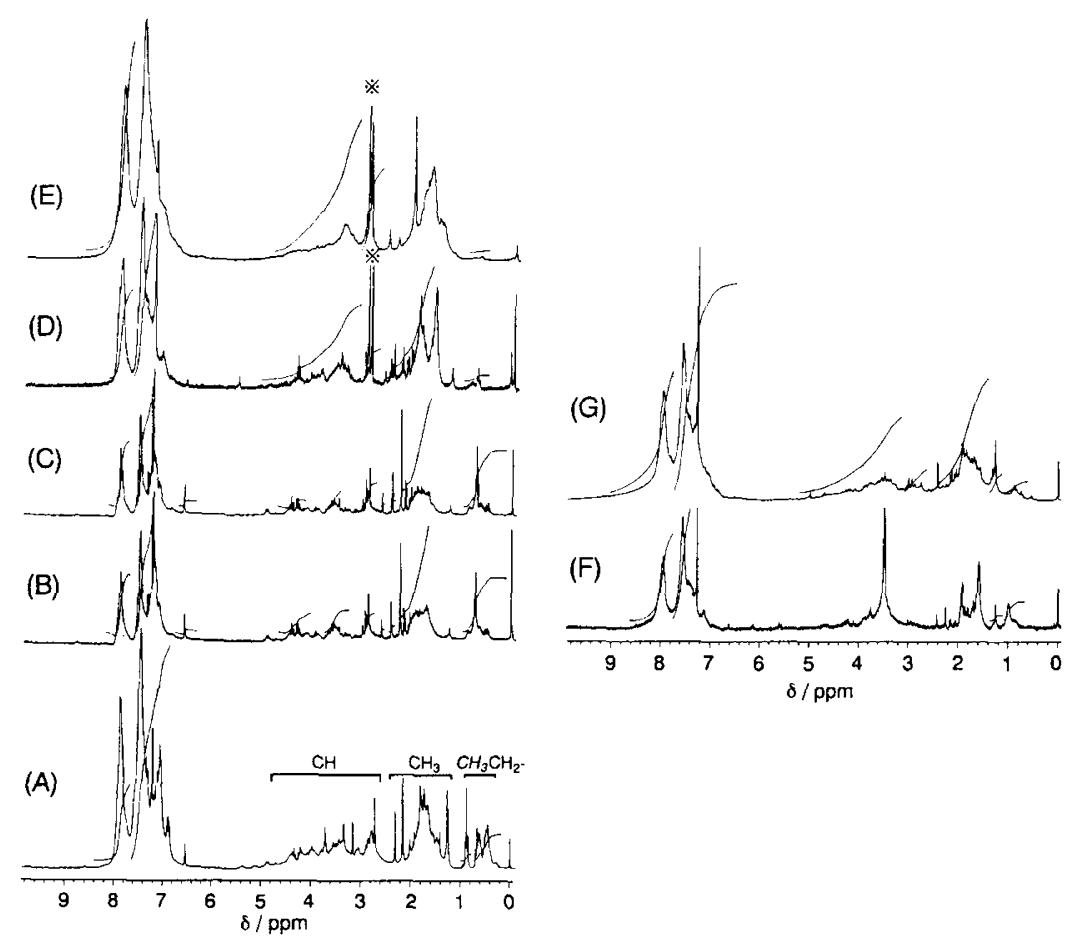

Figure 6. ${ }^{1} \mathrm{H}$ NMR spectra of oligo(NCI)(A, B, C, D, E, F, and G shown in Scheme 3).

\section{CONCLUSIONS}

1. The polymerizations of RCI were carried out with anionic initiators, $\mathrm{RLi}$ or $\mathrm{Et}_{2} \mathrm{Zn}$ in toluene at r.t. to obtain oligomers with $\bar{M}_{n}$ of 400 to 600 .

2. The polymerization of RCI with aryl substituents gave oligomers in high yield. In contrast, RCI with alkyl substituents showed relatively low polymerizability.

3. The asymmetric polymerizations of RCI with chiral ligands/organometal complex gave optically active oligomers having specific rotations of $-40.3^{\circ}$ to + $79.2^{\circ}$. The polymerization with $\mathrm{DDB} / \mathrm{Et}_{2} \mathrm{Zn}$ formed oligo $(\mathrm{PhCI})$ with the highest specific rotation $\left([\alpha]_{435}^{25}\right.$ $=+79.2^{\circ}$ ).

4. Chirality of the RCI oligomer was attributed to chiral carbons produced on the main chain, judging from CD spectra and GPC curves.

\section{REFERENCES}

1. Y. Okamoto and T. Nakano, Chem. Rev., 94, 349 (1994).

2. T. Nakano, N. Kinjo, Y. Hidaka, and Y. Okamoto, Polym. J., 31, 464 (1999).

3. K. Maeda and Y. Okamoto, Macromolecules, 32, 974 (1999). 

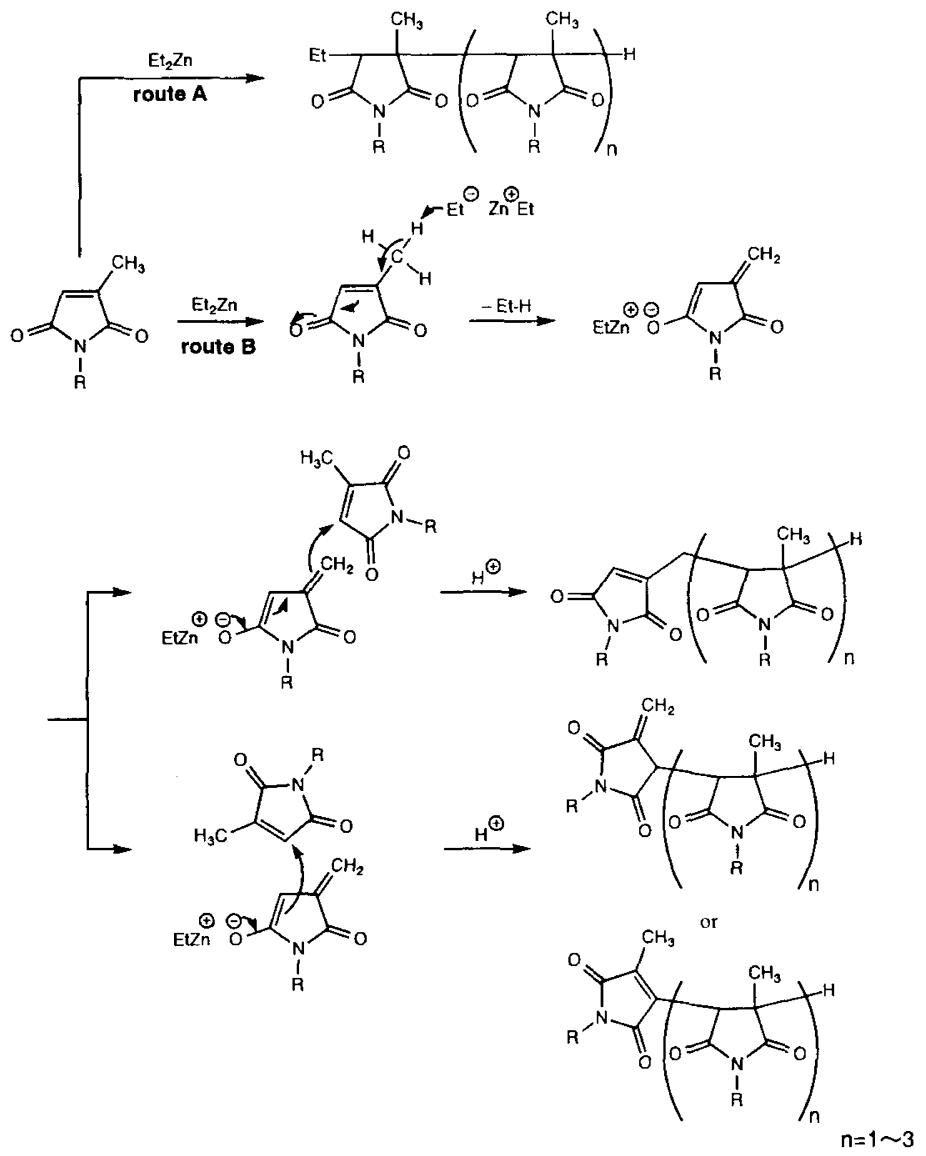

Scheme 4.
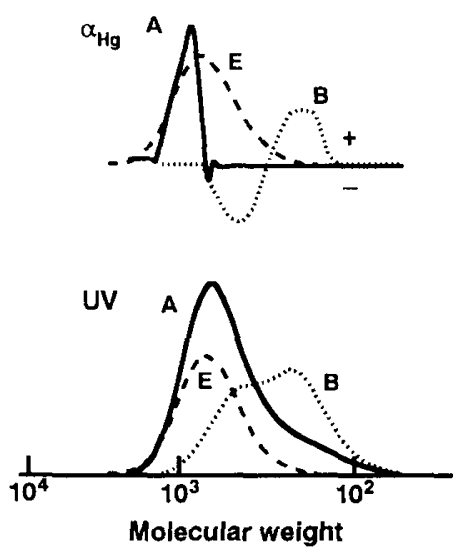

Figure 7. GPC curves of oligo $(\mathrm{NCI})(\mathrm{A}, \mathrm{B}$, and $\mathrm{E})$. Top chromatogram was obtained by polarimetric detection $\left(\alpha_{\mathrm{Hg}}\right)$ and the bottom by UV detection $(254 \mathrm{~nm})$.

4. E. Yashima, K. Maeda, and Y. Okamoto, Nature, 399, 449 (1999).

5. T. Oishi, K. Kagawa, and H. Nagata, Polymer, 38, 1461 (1997).

6. K. Kagawa and T. Oishi, Polym. J., 28, 1 (1996).

7. T. Oishi, K. Kagawa, and M. Fujimoto, J. Polym. Sci., Part A, Polym. Chem., 33, 1341 (1995).

8. K. Kagawa and T. Oishi, Polym. J., 27, 57 (1995).

9. K. Kagawa, T. Oishi, K. Matsusaki, and M. Fujimoto, Polymer, 36, 941 (1995)

10. T. Oishi, H. Yamasaki, and M. Fujimoto, Polym. J., 23, 795 (1991).

11. Y. Okamoto, T. Nakano, H. Kobayashi, and K. Hatada,
Polym. Bull ., 25, 5 (1991).

12. K. Onimura, H. Tsutsumi, and T. Oishi, Polym. Bull ., 39, 437 (1997).

13. K. Onimura, H. Tsutsumi, and T. Oishi, Macromolecules, 31, 5971 (1998).

14. K. Onimura, H. Tsutsumi, and T. Oishi, Chem. Lett., 791 (1998).

15. T. Oishi, K. Onimura K. Tanaka, W. Horimoto, and H. Tsutsumi, J. Polym. Sci. Part A: Polym. Chem., 37, 473 (1999).

16. T. Oishi, K. Onimura, Y. Isobe, and H. Tsutsumi, Chem. Lett., 673 (1999).

17. P. Pino, Adv. Polym. Sci., 4, 393 (1965).

18. G. Natta, M. Farina, M. Peraldo, and G. Bressan, Makromol. Chem., 43, 68 (1961).

19. M. Farina and G. Bressan, Makromol. Chem ., 61, 79 (1963).

20. G. Natta and M. Farina, Tetrahedron Lett., 703 (1963).

21. Y. Takeda, Y. Hayakawa, T. Fueno, and J. Furukawa, Makromol. Chem., 83, 234 (1965).

22. Y. Hayakawa, T. Fueno, and J. Furukawa, J. Poly. Sci. Part A-1., 5, 2099 (1967).

23. T. Oishi, T. Kawamoto, and M. Fujimoto, Polym. J., 25, 1193 (1993).

24. T. Oishi, Polym. J., 12, 799 (1980); 13, 65 (1981); T. Oishi and M. Fujimoto, J. Macromol. Sci., A 23, 619 (1986); T. Oishi, N. Okamoto and M. Fujimoto, J. Polym. Sci., Part A: Polym. Chem., 24, 1185 (1986); T. Oishi, N. Okamoto, and M. Fujimoto, J. Macromol. Sci., A 25, 1039 (1988); T. Oishi, K. Kagawa, and M. Fujimoto, Polym. J., 25, 983 (1993).

25. S. Susumu, S. Shirai, Y. Yoshida, T. Hagiwara, H. Hamana, and T. Narita, 37th Int. Sympo. on Macromol., Preprint, 231 (1998); S. Shirai, Y. Yoshida, T. Hagiwara, H. Hamana, and T. Narita, Chem. Soc. Jpn, Preprint, 296 (1998).

26. P. Y. Reddy, S. Kondo, T. Toru, and Y. Ueno, J. Org. Chem., 67, 2652 (1997).

27. S. E. Denmark, N. Nakajima, O. J.-C. Nicaise, A.-M. Faucher, 
and J. P. Edwards, J. Org. Chem., 60, 4884 (1995).

28. D. Seebach and W. Langer, Helv. Chem. Acta, 60, 301 (1977); D. Seebach, H. O. Kalinowski, W. Langer, G. Crass, and E. M. Wilka, "Organic Syntheses", Wiley, New York, N.Y., Col. Vol. VII, 41 (1990).
29. K. Chikanishi and T. Tsuruta, Makromol. Chem., 81, 198 (1965).

30. N. Kawabata and T. Tsuruta, Makromol. Chem., 86, 231 (1965). 